Bol. Acad. peru. leng. 48. 2009 (11-21)

\title{
GARCILASO COMO FUENTE DE LA LEXICOGRAFÍA PERUANA
}

\author{
GARCILASO COMME SOURCE DE LA \\ LEXICOGRAPHIE PÉRUVIENNE
}

\section{GARCILASO AS A SOURCE OF PERUVIAN LEXICOGRAPHY}

\author{
Carlos Arrizabalaga Lizárraga \\ Universidad de Piura
}

\section{Resumen:}

El glosario que incluyó Andrés González Barcia en su edición de los Comentarios Reales de 1723 (Madrid, Oficina Real, a costa de Nicolás Rodríguez Franco), precedente y base de los glosarios que incluyeron luego Ángel Rosenblat (1943) y Carlos Araníbar (1991), es también una fuente importante de la lexicografía peruana e hispanoamericana. Aunque no hay certeza de que Juan de Arona y Ricardo Palma la tuvieran presente a la hora de realizar sus respectivos repertorios lexicográficos, su ejemplo será seguido por otros editores, como Amador de los Ríos y, en Perú, por Felipe Pardo y Aliaga y el propio Arona.

Résumé:

Le glossaire qu'Andrés González Barcia a inclus dans son édition des Comentarios Reales de 1723 (Madrid, Oficina Real, aux dépens de Nicolas 
Rodríguez Franco), et servant de base aux glossaires qu'Ángel Rosenblat (1943) et Carlos Araníbar (1991) ont inclus ultérieurement, constitue également une source importante pour la lexicographie péruvienne et hispano-américaine. Bien qu'il ne soit pas certain que Juan de Arona et Ricardo Palma l'aient pris en considération lors de la création de leurs répertoires lexicographiques respectifs, leur exemple sera suivi par d'autres éditeurs, tels qu'Amador de los Rios et, au Pérou, Felipe Pardo y Aliaga, ou encore Arona.

\section{Abstract:}

The glossary that Andrés Gonzalez Barcia included in his edition of the Comentarios Reales of 1723 (Madrid, Oficina Real at the cost of Nicolás Rodríguez Franco), a base for the glossaries that Ángel Rosenblat (1943) and Carlos Araníbar (1991) compiled, is an important source of the Peruvian and Spanish-American lexicography. Though there is no certainty that Juan de Arona and Ricardo Palma had them in mind at the moment of realizing their lexicographical digests, his example was followed by other publishers as Amador de los Ríos and, in Peru, by Felipe Pardo y Aliaga, and Arona himself.

Palabras clave:

Metalexicografía; español de Perú; Inca Garcilaso; fuentes lexicográficas; historiografía lingüística; diccionarios; glosarios; Juan de Arona; Ricardo Palma.

Mots clés:

Metalexicographie; l'espagnol du Pérou; l'Inca Garcilaso; sources lexicographiques; historiographie linguistique; dictionnaires; glossaires; Juan de Arona; Ricardo Palma.

Key words:

Metalexicoghaphy; Spanish of Peru; Inca Garcilaso; lexicographical souces; linguistic historiography; dictionaries; glossaries; Juan de Arona; Ricardo Palma. 
Fecha de recepción:

$04 / 07 / 2009$

Fecha de aceptación:

$12 / 11 / 2009$

Enrique Carrión Ordóñez puso de relieve en 1983 la existencia de compilaciones de peruanismos anteriores a Arona, particularmente la lista de voces que incluyó el presbítero Antonio Pereira y Ruiz en su Noticia de Arequipa y la que incluyó Ramón Soler en su novela Adela y Matilde, o los últimos cinco años de dominación española en el Perú (Madrid, 1843). En realidad Juan de Arona ignoró ambos, pero Ricardo Palma sí incluyó quechuismos todavía usuales entresacados del repertorio de Soler en el suplemento de sus Papeletas (1903). Con anterioridad Aurelio Miró Quesada (1969) destacó que otro precedente fue precisamente Felipe Pardo y Aliaga, que también había recopilado términos como jalar, o rancho y otros términos que Arona incluye en su Diccionario indicando en algunos su obsolescencia (como en pinganilla). El propio Arona hará lo propio glosando algunos términos en sus Cuadros y episodios peruanos (1867).

La lexicografía se nutre en realidad de toda palabra hablada o escrita, de toda manifestación del lenguaje, así que toda expresión lingüística le sirve de fuente, pero son las circunstancias muchas veces las que motivan un desarrollo u otro y, fundamentalmente todos los repertorios anteriores que configuran la tradición discursiva en que se insertan, evolucionando junto con las mentalidades y la historia política de los pueblos. La lexicografía regional nace en Latinoamérica como no podría ser de otro modo, por la misma necesidad de hacer inteligible una realidad separada, y cuando la separación tiene ya cariz de independencia política y social la lexicografía se convierte también en ámbito de debate y emblema de orgullo nacional (Torrejón, 1991).

El temprano Alfabeto de las mercaderías que se avalian en Panamá, escrito por dos oficiales reales, Tristán de Silva Campofrío y Agustín de Haro el 6 de mayo de 1575 y conservado en el Archivo de Indias, surgió por necesidad. Recoge simplemente los nombres de "las mercaderías que entran en el puerto desta dicha ciudad [Panamá] por la mar del sur”. Si alguna vez las palabras viajaron con las cosas, dice Eva María Bravo, quien descubrió el manuscrito en 1994, fue en el proceso de conquista 
y población de América". Luego vendrán las glosas o tablas "para la inteligencia de algunos vocablos" que incluye, en primer lugar, fray Pedro Simón, el léxico de Manuel José de Ayala (1751) hasta llegar al vocabulario de "voces provinciales de América" del funcionario español Antonio de Alcedo (1789), que se convertirá en la referencia fundamental para los posteriores diccionarios particulares de cada nación, comenzando por el Diccionario de voces cubanas de Esteban Pichardo, de 1836, los de Zorobabel Rodríguez en Chile (1875) y Arístides Rojas en Venezuela (1882), hasta llegar al Diccionario de peruanismos de Arona en 1884.

El primer repertorio de peruanismos conocido se encuentra en la primera edición del Arauco Domado de Pedro de Oña (1596), aunque se trate de un glosario de apenas ocho indigenismos, entre los que se encuentran chicha, macana o molle. También es muy temprano, como señaló Luis Jaime Cisneros, el glosario que incluyó en su Miscelánea Austral (1602) el también limeño Diego Dávalos y Figueroa, quien afirma con rotundidad: "tenemos ya por inseparables algunos vocablos destas [lenguas] bárbaras, y las usamos como si en la nuestra faltasen mejores términos para aquello mesmo" (125).

A estos precedentes, ya estudiados por Luis Jaime Cisneros y por Rodolfo Cerrón-Palomino, pienso que habría que añadirse la "Tabla de las cosas notables, y personas, contenidas en el primer tomo de los Comentarios Reales del Inca Garcilaso de la Vega”. Es el apéndice que incluyó Andrés González Barcia (utilizando el seudónimo de Gabriel de Cárdenas), en su edición de $1723^{1}$ de esas preclaras páginas ya cuatrocentenarias "que tratan, de el origen de los incas, reies, que fueron del Perú, de su idolatría, leies, y Govierno, en Paz, y en guerra, de sus vidas, y conquistas...” Esa tabla, que ocupa una extensión de treinta y tres páginas en tres columnas, incluye en sí un verdadero glosario lexicológico anterior a la Noticia de Arequipa y también al propio Alcedo. Registra especialmente numerosos quechuismos consignando su respectiva equivalencia con la abreviatura $S$

1 Madrid, Nicolás Rodríguez Franco, 351 p. Agradezco a mi estimado amigo, el profesor Ricardo Huamán por haberme proporcionado una copia de este material, que se halla en la Biblioteca Nacional de Madrid. 
de que "significa" lo que sigue: Aca, Estiércol; Acatanca, Escarabajo; Aclla, Casa de Escogidas; Alco, Perro, Amancay, Açucena; Amaru, Culebra grande; Aquilla, Vaso de Oro, Añus, legumbre; Añas, Animalejos muy hediondos, menores que gatos; Anta, Cobre; Apú, Capitán; Atoc, Zorra. Auca, Traidor, Tirano y otras cosas semejantes; Ayllu, linaje. A veces se hace eco de las aclaraciones semánticas, ortográficas, pragmáticas o etimológicas del Inca: Amautas, se llamaban los Sabios y Filósofos de los Indios; Apachita (voz corrompida de Apachecta), la Cuesta; Ayusca, el Encanijado, y es palabra ofensiva a los Casados. Registra equivalencias entre batata y apichu, o entre aji y uchu. La mayoría son quechuismos, pero también aparecen maguey, guayaba, amén de las dichas. Aparece también algún americanismo: piña, loro, y un arcaísmo castellano: rodela, descrita como "arma única defensiva de los indios".

Salteados entre una minuciosa información enciclopédica y en función a sus remisiones en el texto se encuentran, pues, toda una serie de brevísimas papeletas lexicográficas que constituyen, a mi modo de ver, uno de los primeros registros ordenados de peruanismos.

No sabemos si Arona y Palma pudieron tener en sus manos esta edición de los Comentarios, aunque lo más probable es que hubieran utilizado alguna posterior: la de Villalpando (1729), o más seguramente la de los hijos de Piñuela (1800-1801), que salieron sin tabla de materias. Hay coincidencias muy explicables en la redacción de entradas como cancha, "maíz tostado", pero muchas más diferencias: Arona registra huminta como étimo de humita mientras que la González Barcia consigna humintu, "el Pan de maíz, para comer". Tampoco coincide la ortografía de haylli (hailli en la Tabla), ni todas las entradas corresponden, porque la Tabla no consigna, por ejemplo, el término huano (al que Arona dedica largos párrafos) mientras que Arona no consigna illapa, que tiene tres remisiones en la Tabla (Arrizabalaga, 2009).

Con todo, la cantidad de veces en que Arona menciona a Garcilaso (a diferencia de Palma que no lo cita nunca), parece apoyar la idea de que Arona tuvo en sus manos esa edición de los Comentarios, que le ofrecían los lugares exactos en que se aparece cada término. 
De todos modos Paz Soldán utiliza en su diccionario muy diversas fuentes para autorizar sus entradas, como las crónicas de Cieza de León (1553), Agustín de Zárate (1555), y la Historia general de las Indias de López de Gómara (1552), además del Sumario y la Historia general y natural de las Indias de Fernández de Oviedo, y la Historia natural y moral de José de Acosta, entre otros.

Si es que Arona no tuvo en sus manos la "Tabla de materias" de la edición de González Barcia, este fue un eslabón necesario en el camino que haría posible el desarrollo de la lexicografía hispanoamericana, ya que Alcedo no pudo ignorarla a la hora de elaborar su Vocabulario de las voces provinciales de América y así también la Historia general y natural de las Indias de Fernández de Oviedo, había sido publicada por Amador de los Ríos, en cuatro magníficos volúmenes entre los años 1851 y 1855, con un nutrido glosario: "Voces americanas empleadas por Oviedo" que van seguidas de una breve bibliografía de gramáticas y vocabularios tempranos de las lenguas indígenas. Ocupan las páginas 593 a 608 del cuarto volumen y fueron una fuente importante para Juan de Arona.

De todas maneras Garcilaso se presentaba como "intérprete de vocablos" y en su texto hay numerosas disquisiciones lingüísticas, como señalan Alberto Escobar (1960) y Aurelio Miró Quesada (1974), así que basta leer el texto para entresacar multitud de papeletas lexicográficas.

También Ricardo Palma tuvo también en cuenta las obras de Garcilaso (fuente de varias de sus Tradiciones), pero sólo se apoya en su autoridad en la entrada de quipucamayo, pero también es que no busca apoyos para autorizar sus papeletas, sino que sigue el método propuesto por el gaditano Eduardo Benot, que trataba de no atender tanto a las obras anteriores sino a los hechos mismos que el lingüista comprueba directamente en el hablar, pone la lengua por delante de la lingüistica:

"Cuando encuentro una palabra, en la conversación o en mis lecturas, que me parece necesaria o apropiada, y que no se halla en el Diccionario, sin pérdida de minuto la consigno en mi cartera de apuntes para después estudiarla y alambicarla.” (1903: IX) 
No debe extrañar a nadie, en cambio, que Garcilaso tenga una presencia notable en la obra de Arona. Al fin y al cabo, los Comentarios constituían una autoridad indiscutible para su época; aún más lo fue igualmente, como lo ha estudiado la profesora Nelly Trelles Castro, para los que elaboraron el primer Diccionario de la Real Academia Española. Citas de los Comentarios del Inca aparecen en Autoridades desde el primer tomo (1726), no solamente para autorizar indoamericanismos como maguey, sino también términos castellanos antiguos, como "mamujar".

Juan de Arona no solamente toma en cuenta la opinión del cuzqueño, que había mamado el quechua en la leche materna, sino que le dedica una atención extraordinaria, verdaderamente abrumadora en el número de voces autorizadas por el Inca. La autoridad de Garcilaso pesa tanto en el alma de Arona que le asigna erróneamente un origen quechua al aztequismo petaca (que es desde el XVIII al menos, americanismo de uso general) porque lo consigna Garcilaso y, más aún, iporque Garcilaso lo autoriza en el Diccionario de Autoridades! ${ }^{2}$

Por otra parte Arona leyó con suma atención los distintos números del Mercurio, y prueba de ello es que hace frecuentemente referencia a los artículos de la revista que fundara su abuelo materno. Como ejemplo las referencias que pone a la voz barchilón, caja de agua o de huayrona, y justamente en la explicación que da a coca Arona alude al estudio de su abuelo, el prócer Hipólito Unanue, quien a su vez se apoya en Garcilaso, porque la noticia que da el cuzqueño es la mejor de los cronistas.

Con todo, Arona se muestra despegado de las fuentes peruanas en la ortografía, en donde se manifiesta defensor del uso moderno común. Arona prefiere escribir caigua y no cayhua como lo hacía Garcilaso.

Así también moderniza la ortografía de airampo ("del quechua ayrampu" (64). Aborda finalmente la cuestión en la entrada de aymará (91),

2 Quizás también porque Garcilaso lo pone en boca de los indios chiriguanas aclarando "es canasta cerrada" ([1609] 1985: 304). 
declarándose partidario de la forma castellana: aimará pero reconociendo que "la ortografía de esta palabra como la de airampo y otras por el estilo es arbitraria. Unos la escriben con y griega y otos con $i$ latina" (91).

Sin acudir a ninguna fuente Arona prefiere quichua a quechua que era la forma de uso entonces mayoritario, tal vez influido por los quechuistas del siglo XIX. Arona finalmente señala que humita ("del quechua huminta") se escribe con hache porque los españoles recién llegados "acaso creyeron percibir en la pronunciación de los indígenas alguna ligera aspiración" (243), pero lo hace en respuesta al chileno Paulsen, quien disparatadamente piensa que la hache de humita se debía a que "se dejaron llevar sin duda de la semejanza de humita con el diminutivo de humo".

Arona polemiza con unos y con otros defendiendo unas veces un término y atacando si no le parece bien algún otro, como en el caso de voltear, en que le parece una barbaridad una palabra que es hoy tan normal. Por todo eso reconoce Carrión que "el libro tiene poco de lo que hoy exigimos a una obra lexicográfica” (148). Y concluye:

"El Diccionario de Peruanismos es, pues, una compilación de textos de tipo literario, donde abunda la información lingüística mezclada con diversas consideraciones correctivas y digresiones enciclopédicas" (149)

La lexicografía posterior encontrará ya en el siglo XX el camino indicado. En 1953 Rubén Vargas Ugarte publica un Glosario de peruanismos reuniendo los que no hallaba citados en el Diccionario de la Academia, ni "en el magnífico del jesuita Terreros, ni en el de Peruanismos de nuestro compatriota D. Pedro Paz Soldán y Unanue” (5). El copioso vocabulario prometido por Murrieta todavía no ve la luz ${ }^{3}$ y en su lugar se publican los repertorios del embajador Álvarez Vita (1990) que acaba de reeditarse (2009) y póstumamente el del profesor Miguel Ángel Ugarte Chamorro (1997).

$3 \quad$ Ver Vargas (2005). 
Podemos afirmar con toda seguridad que la lexicografía peruana no habría tenido un desarrollo semejante si no hubiera sido por las obras del Inca Garcilaso. Así como las ediciones de sus Comentarios Reales tuvieron un impacto notable sobre la evolución cultural y política del Perú, especialmente en la época anterior y posterior a la Independencia, en que una población piurana tomaría el nombre de Sullana simplemente porque así se mencionaba en los Comentarios aunque todas las demás crónicas mencionasen el lugar (en una ubicación no tan cercana) con el nombre de La Solana; así también la edición que hizo el notable bibliógrafo español Andrés González Barcia en 1723 (sin duda contagiado por ese "intérprete de vocablos" que quiso ser Garcilaso) tuvo una repercusión si no inmediata, muy importante no sólo en la incorporación de peruanismos en el primer diccionario académico, sino en la posibilidad de que los americanismos entrasen por la puerta grande en la Academia y más importante aún en la propia conciencia de los hablantes; y que así también, un siglo después, Juan de Arona pusiera el apelativo de peruanismos a los términos que incluyó en el primer repertorio lexicográfico de este país, muchos de los cuales ya habían entrado en la pluma del Inca.

\section{BIBLIOGRAFÍA}

ÁLVAREZ VITA, Juan. Diccionario de peruanismos. Lima, Studium, 1990. Hay una segunda edición en Lima, Universidad Alas Peruanas, 2009.

ARRIZABALAGA, Carlos. "Garcilaso como autoridad en el Diccionario de peruanismos de Arona”, en C. Arrizabalaga y M. Prendes (eds.), Este gran laberinto. Estudios sobre el Inca Garcilaso en el centenario de los Comentarios Reales. Piura, Universidad de Piura, Universidad de Navarra y Academia Peruana de la Lengua, págs. 95-120, 2009.

. (en prensa), "Garcilaso y el nombre de Sullana", Actas del Congreso Internacional "Las palabras de Garcilaso" (23, 24 y 25 de abril de 2009), Lima, Academia Peruana de la Lengua. 
BRAVO GARCÍA, Eva M. "Un desconocido vocabulario del siglo XVI: el "Alfabeto de las mercaderías que se avalían en Panamá", en Philologica hispalensis, N. ${ }^{\circ}$ 9, págs. 147-159, 1994.

CARRIÓN ORDÓÑEZ, Enrique. "Compilaciones de peruanismos anteriores a Arona", Boletín de la Academia Peruana de la Lengua, N. ${ }^{\circ} 14$, págs. 147-162, 1983.

CISNEROS VIZCARRA, Luis Jaime. "Notas sobre la Miscelánea Austral de Diego Dávalos y Figueroa”, Revista Histórica, N. 19, págs. 286-327, 1952.

DÁVALOS Y FIGUEROA, Diego. Primera parte de la Miscelánea Austral, Lima, Imprenta de Antonio Ricardo, 1602.

ESCOBAR, Alberto. "Lenguaje e historia en los Comentarios Reales", en Sphinx 13. Reproducido en Patio de letras, Caracas, Monte Avila, 1971, págs. 7-44, 1960.

MIRÓ QUESADA, Aurelio. "Felipe Pardo en la Academia", Boletín de la Academia Peruana de la Lengua. N. ${ }^{\circ}$ 3, págs. 23-52, 1969. . "Las ideas lingüísticas del Inca Garcilaso", en Boletín de la Academia Peruana de la Lengua, N. 9, págs. 27-64. Reproducido en Tiempo de leer. Tiempo de escribir. Lima, P. L. Villanueva Editores, 1977, págs. 11-49, 1974.

PALMA SORIANO, Ricardo. Neologismos y americanismos. Lima, Librería e Imprenta de Carlos Prince, 1896.

. Papeletas lexicográficas. Lima, Imprenta La Industria. Hay una edición facsímil reciente con prólogo de Martha Hildebrandt: Lima, Academia Peruana de la Lengua y Universidad San Martín de Porres, [1903] 2003.

PAULSEN, Fernando. Reparos de reparos, o sea, lijero examen de los reparos al diccionario de chilenismos de Don Zorobabel Rodriguez por Fidelis Pastor del Solar. Santiago de Chile, Imprenta de «La estrella de Chile”, 1876. 
PAZ SOLDÁN Y UNANUE -Juan de Arona-. Cuadros y episodios peruanos. Lima, Imprenta de M. Noriega, 1867.

. Diccionario de peruanismos, edición de Estuardo Núñez. Lima, Peisa, [1884] 1974.

QUESADA PACHECO, Miguel Ángel. "Hispanoamérica y la Real Academia Española”, Revista Nacional de Cultura, San José (Costa Rica), N. ${ }^{\circ}$ 39, págs. 21-32, 2000.

TORREJÓN, Alfredo. «El castellano en América en el siglo XIX: creación de una nueva identidad lingüística», en César Hernández, et al. (1992), El español de América. Tomo I, Salamanca, Junta de Castilla y León, págs. 361-370, 1991.

TRELlES CASTRO, Nelly. "El Inca Garcilaso en el Diccionario de Autoridades", en C. Arrizabalaga y M. Prendes (eds.), Este gran laberinto. Estudios sobre el Inca Garcilaso en el centenario de los Comentarios Reales, Piura, Universidad de Piura, págs. 59-70, 2009.

UGARTE CHAMORRO, Miguel Ángel. Vocabulario de peruanismos, Lima, Universidad Nacional Mayor de San Marcos, 1997.

VARGAS DURAND, Luis. "Las papeletas lexicográficas de Pedro Benvenutto Murrieta”, en C. Arrizabalaga (ed.), Coloquios de lingüistica. Piura, Universidad de Piura, págs. 141-160, 2005.

VARGAS UGARTE, Rubén. Glosario de peruanismos, Lima, 1953.

\section{Correspondencia:}

Carlos Arrizabalaga Lizárraga

Docente de la Universidad de Piura.

Correo electrónico: carlos.arrizabalaga@udep.pe 